\title{
Kemampuan Gerak Dasar Renang Gaya Dada Pada Siswa Menengah Pertama
}

\section{Basic Movement Style Swimming Ability in Junior High Students}

\section{Anak Agung Ngurah Putra Laksana*, I Wayan Adnyana, I Kadek Yudha Pranata, Ida Ayu Kade Arisanthi Dewi}

\author{
Fakultas Keguruan dan Ilmu Pendidikan, Universitas PGRI Mahadewa Indonesia Jl. Seroja No.57, Bali, 80235, \\ Indonesia \\ e-mail: agungputralaksana@gmail.com, iwayanadnyana749@gmail.com, ypbrandedwear@gmail.com, \\ idaayukadearisanthidewi@gmail.com
}

\begin{abstract}
Abstrak
Penelitian ini bertujuan untuk mengetahui kemampuan gerak dasar renang gaya dada pada siswa kelas VII 4 SMP Negeri 5 Kuta Selatan. Jenis penelitian ini adalah deskriptif kualitatif. Sampel terdiri dari 5 siswa dan 1 orang guru. Teknik pengumpulan data menggunakan triangulasi yaitu observasi, wawancara, dan kuesioner. Adapun analisis data yang digunakan yaitu analisis Miles dan Huberman yaitu analisis data model interaktif yang melalui langkah-langkah pengumpulan data, reduksi data, penyajian data, dan penarikan kesimpulan. Hasil penelitian ini menunjukkan bahwa cukup maksimal kemampuan siswa dalam melakukan gerak dasar renang gaya dada yaitu kategori (baik). Dengan persentase hasil nilai observasi sebanyak 18 siswa (60\%) berada di kategori baik dan sebanyak 12 siswa (40\%) berada dalam kategori cukup. Hasil data wawancara menunjukkan sudah cukup maksimal proses pembelajaran. Karena sedikit faktor penghambat. Hasil data kuesioner menunjukkan sebanyak 18 siswa (60\%) dalam kategori baik dan sebanyak 12 siswa (40\%) berada dalam kategori cukup. Berdasarkan hasil penelitian tersebut dapat diartikan bahwa pembelajaran gaya renang dada pada siswa dapat ditingkatkan atau didorong dari kemampuan gerak yang dimiliki oleh siswa tersebut.

Kata kunci: Kemampuan, Gerak Dasar, Renang Gaya Dada.

\section{Abstract}

This study aims to determine the basic movement skills of breaststroke swimming in class VII 4 SMP Negeri 5 Kuta Selatan. This type of research is descriptive qualitative. The sample consisted of 5 students and 1 teacher. The data collection technique used triangulation, namely observation, interviews, and questionnaires. The data analysis used is the analysis of Miles and Huberman, namely an interactive model of data analysis through data collection steps, data reduction, data presentation, and drawing conclusions. The results of this study indicate that the students' ability to perform the basic movements of breaststroke swimming is sufficiently maximum, namely the (good) category. With the percentage of the results of the observation score as many as 18 students (60\%) were in the good category and as many as 12 students (40\%) were in the sufficient category. The results of the interview data showed that the learning process was sufficiently maximal. Due to a few inhibiting factors. The results of the questionnaire data showed that as many as 18 students (60\%) were in the good category and as many as 12 students (40\%) were in the sufficient category. Based on the results of this study, it can be interpreted that learning breaststroke in students can be increased or encouraged by the ability of the students to move.

Keywords: Ability, Basic Motion, Chest Style Swimming.
\end{abstract}

corresponding author: agungputralaksana@gmail.com

Artikel Info:

Submitted: 06/02/2021

Revised : 16/04/2021

Accepted : 15/05/2021

Published: 17/05/2021

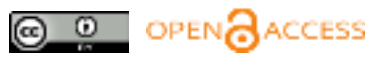

Journal Coaching Education Sports is licensed under a Creatives Commons Attribution 4.0 International License

Copyright @ 2021 


\section{A. Pendahuluan}

Pendidikan jasmani olahraga dan kesehatan memiliki karakteristik khusus berupa aktifitas fisik (jasmani) (Pujianto et al., 2020). Aktifitas inilah yang merupakan indikator utama sebagai media kegiatan pendidikan jasmani dan olahraga (Maulana et al., 2018). Oleh karena itu penguasaan konsep tentang gerak dan belajar motorik (gerak) merupakan hal penting yang harus dikuasai siswa dan guru pendidikan jasmani sebagai bekal dalam melaksanakan kegiatan belajar mengajar (Mustafa et al., 2019).

Tujuan pendidikan jasmani olahraga dan kesehatan ialah membentuk anak menjadi seseoang yang mempunyai kecakapan praktis dan dapat memecahkan masalah sosial sehari - hari dengan baik (Widodo, 2018). Pendidikan jasmani olahraga dan kesehatan memiliki peranan penting dalam penyelenggaraan pendidikan sebagai suatu proses pembinaan manusia yang berlangsung seumur hidup (Arifin, 2017).

Dalam pelaksanaanya aktivitas jasmani digunakan sebagai wahana pengalaman belajar siswa tumbuh dan berkembang demi mencapai tujuan pendidikan (Purnomo Adi Pratama et al., 2020). Tujuan pembelajaran dapat dilihat berdasarkan pokok - pokok bahasan bidang studi yang disampaikan disekolah terdiri dari enam pokok bahasan, lima pokok bahasan, seperti olahraga permainan, atletik, senam, teori kesehatan, dan pendidikan luar sekolah dapat dilaksanakan tanpa hambatan (Suherman, 2001). Lain halnya untuk aktivitas air atau renang yang memiliki media yang berbeda yaitu harus dilakukan di kolam renang dan harus memiliki kemampuan yang baik dalam melakukan gerak-gerak dasar renang (Alvian \& Nuruddin, 2019).

Kemampuan berasal dari diri seseorang dalam melakukan aktifitasnya. Hal senada juga disampaikan oleh (Paramitha \& Anggara, 2018) kemampuan merupakan bawaan kesanggupan sejak lahir atau merupakan hasil dari latihan yang digunakan untuk melakukan suatu pekerjaan. Kemampuan tersebut meliputi kemampuan fisik dan kemampuan intelektual. (Kamadi, 2020) juga menyatakan kemampuan adalah tanggung jawab karakteristik yang luas dan stabil untuk kinerja maksimal seseorang pada tugas fisik dan mental. Sedangkan menurut (Illahi, 2019) bahwa kemampuan adalah kapasitas seseorang untuk melaksanakan beberapa kegiatan dalam suatu pekerjaan.

Berdasarkan pendapat ahli tersebut dapat disimpulkan bahwa kemampuan adalah 
kecakapan atau kesanggupan yang diperlukan seseorang untuk melakukan kegiatan atau aktivitas secara maksimal pada tugas fisik atau mental dalam melakukan aktifitas.

Menurut (Mustafa \& Dwiyogo, 2020) sangat penting mempelajari keterampilan gerak dasar pada usia dini karena apabila kurang cukup diajarkan tentang keterampilan gerak dasar, anak akan mengalami berbagai hambatan dalam mempelajari dan melakukan berbagai keterampilan gerak yang lebih sulit di kemudian hari, seperti mempelajari keterampilan teknik olahraga (sport skill) nantinya.

Gerak dasar yang paling sering dilakukan oleh anak dalam setiap aktivitasnya adalah gerak dasar lokomotor yang terdiri atas gerakan jalan, lari, lompat dan loncat. Dalam kehidupan sehari-hari, manusia dari usia anak-anak sampai usia dewasa selalu melakukan kegiatan gerak dasar lokomotor (Dimyati, 2017).

Sedangkan Menurut (Arifin, 2017) menyebutkan bahwa gerak dasar merupakan dasar macam-macam keterampilan yang sangat perlu adanya bimbingan, latihan, dan pengembangan agar anak dapat melaksanakan dengan tangkas. Hal ini dapat membantu anak untuk melepaskan diri dari ketergantungan kepada orang lain dan juga merupakan bagian dari perkembangan intelektual. Dapat disimpulkan gerak dasar adalah suatu pola yang mendasari suatu gerakan mulai dari kemampuan gerak yang sederhana hingga kemampuan gerak yang kompleks.

Gerak dasar diperlukan siswa dalam melakukan olahraga renang. Renang dilakukan dari usia anak-anak sampai dewasa, bahkan sampai usia lanjut (Erliza, 2018). Menurut (Rizkiyansyah \& Mulyana, 2019),"Renang adalah termasuk olahraga yang telah dikenal sejak zaman prasejarah. Menurut (Arhesa, 2020), "Olahraga renang telah terbagi beberapa macam gerakan atau gaya. Gaya renang yang lazim digunakan ada empat macam gaya yaitu gaya crawl (bebas), gaya dada (katak), gaya punggung, dan gaya dolphin (kupu-kupu) (Alvian \& Nuruddin, 2019).

Pendapat lain mengatakan bahwa Olahraga renang merupakan keterampilan gerak yang dilakukan di air yang bertujuan untuk bersenang - senang, mengisi waktu luang dan mendapatkan prestasi di tingkat nasional maupun internasional (Thomas, 2013). Berdasarkan pendapat ahli di atas dapat disimpulkan bahwa renang merupakan olahraga yang dilaksanakan di air dengan berbagai macam gaya yang dapat 
dilakukan, seperti gaya crawl (bebas), gaya dada (katak), gaya punggung, dan gaya dolphin (kupu-kupu). Olahraga renang dapat dilaksanakan untuk mengisi waktu luang, dalam proses pembelajaran, maupun sebagai olahraga prestasi. (Tahapary \& Syaranamual, 2020) mengatakan terdapat 5 teknik Renang Gaya dada : 1) gerakan meluncur; 2) Gerakan Kaki; 3) Gerakan Tangan; 4) Mengambil Nafas; 5) Gerakan Koordinasi.

Menurut (Wulandari, 2014) masa usia sekolah menengah pertama bertepatan dengan masa remaja. Masa remaja merupakan masa yang banyak menarik perhatian karena sifat-sifat khasnya dan perannya yang menentukan dalam kehidupan individu dalam masyarakat orang dewasa.

Masa remaja di bagi menjadi beberapa bagian, yakni masa remaja awal merupakan masa remaja dengan kemampuan yang dimiliki oleh siswa terlihat lebih menurun. Sering kali siswa cenderung lebih pesimis, malas dalam bekerja dan sebagainya. Untuk itu dalam tahap ini, perlu adanya dorongan dan dukungan dari guru agar dapat meningkatkan semangat serta kemampuan yang dimiliki oleh siswa (Adriansyah \& Rahmi, 2012). Selanjutnya tahap remaja madya dimana tahap ini seorang siswa sudah menyadari arti kehidupan serta dapat menentukan jati diri mereka (Wulandari, 2014). Pada tahapan ini, seorang guru diharapkan dapat membimbing siswa agar mencapai arah dan tujuan yang diinginkannya.

Berdasarkan observasi di SMP Negeri 5 Kuta Selatan, terdapat beberapa siswa yang masih stug pada masa remaja awal. Siswa cenderung tidak memiliki kemampuan dalam melakukan aktifitas olahraga khususnya pada saat mata pelajaran praktik renang. Mereka cenderung menganggap remeh pelajaran tersebut. Mereka beranggapan renang dapat dilakukan siapa saja tanpa teknik yang khusus. Untuk itu, perlu adanya tinjauan serta analisis khusus yang perlu dilakukan dalam melihat kemampuan siswa SMP 5 Kuta Selatan dalam melakukan gaya renang dada.

\section{B. Metode Penelitian}

Tujuan dari penelitian ini adalah untuk mengetahui kemampuan gerak dasar renang gaya dada pada siswa kelas VII 4 SMP Negeri 5 Kuta Selatan. Jenis penelitian merupakan deskriptif kualitatif. Adapun informan dalam penelitian ini adalah 30 siswa dari SMP Negeri 5 Kuta Selatan.

Instrumen tes yang digunakan dalam penelitian ini berupa pengamatan dan 
perhitungan langsung, data skunder yang digunakan yaitu data wawancara dan kuesioner. Teknik pengumpulan data menggunakan triangulasi yaitu observasi, wawancara, dan kuesioner.

Adapun analisis data yang digunakan yaitu analisis Miles dan Huberman yaitu analisis data model interaktif yang melalui langkah-langkah pengumpulan data, reduksi data, penyajian data, dan penarikan kesimpulan. Pola analisis interaktif yang dikemukakan oleh miles dan Huberman dalam (Nugrahani et al., 2014) dapat dilihat dalam gambar berikut:

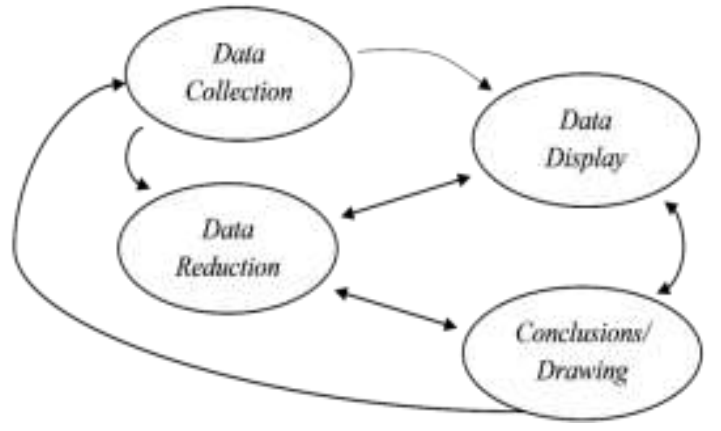

Gambar.3.1. Analisis Data Model Interaktif. (Sumber: Miles dan Huberman dalam Nugrahani, 2014)

\section{Hasil dan Pembahasan}

\section{Hasil}

Hasil penelitian ini menunjukkan bahwa cukup maksimal kemampuan siswa dalam melakukan gerak dasar renang gaya dada yaitu kategori (baik). Dengan persentase hasil nilai observasi sebanyak 18 siswa
(60\%) berada di kategori baik dan sebanyak 12 siswa (40\%) berada dalam kategori cukup. Hasil data wawancara menunjukkan sudah cukup maksimal proses pembelajaran. Karena sedikit faktor penghambat. Hasil data kuesioner menunjukkan sebanyak 18 siswa $(60 \%)$ dalam kategori baik dan sebanyak 12 siswa (40\%) berada dalam kategori cukup.

\begin{tabular}{|c|c|c|c|c|c|}
\hline No & $\begin{array}{c}\text { Rentang } \\
\text { Skor }\end{array}$ & Kategari & $\begin{array}{r}\text { Jumlah } \\
\text { Siswa }\end{array}$ & $\begin{array}{l}\text { Persentase } \\
\text { Siswa }\end{array}$ & $\begin{array}{l}\text { Ketuntasan } \\
\text { Siswa }\end{array}$ \\
\hline 1. & $90-100$ & $\begin{array}{c}\text { Sangat } \\
\text { Baik }\end{array}$ & 0 siswa & $0 \%$ & \multirow{2}{*}{$\begin{array}{c}60 \% \\
\text { mampa } \\
\text { melakukan } \\
\text { gerak dasar } \\
\text { renang gaya } \\
\text { dada }\end{array}$} \\
\hline 2. & $75-89$ & Baik & 18 siswa & $60 \%$ & \\
\hline 3. & $60-74$ & Cukup & 12 siswva & $40 \%$ & \multirow{2}{*}{$\begin{array}{c}40 \% \text { siswa } \\
\text { belum } \\
\text { Marngu } \\
\text { melakukan } \\
\text { gerak dasar }\end{array}$} \\
\hline 4. & $0-59$ & Kurang & 0 - siswa & $0 \%$ & \\
\hline & \multicolumn{2}{|c|}{ Jumlah } & 30 sistva & $100 \%$ & $100 \%$ \\
\hline
\end{tabular}

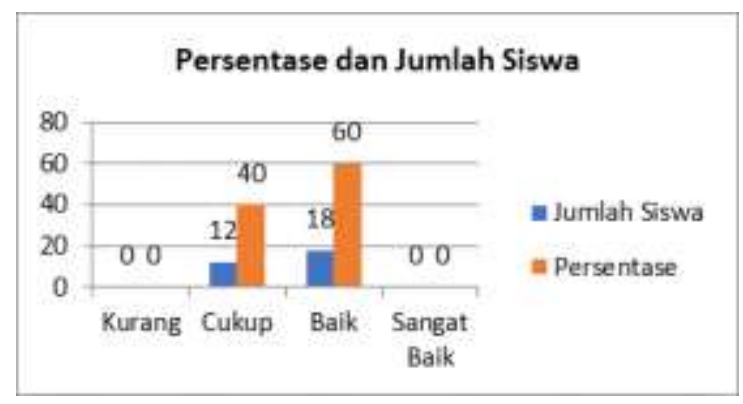

Dari data yang di diperoleh pada saat observasi nilai yang didapat cukup baik. Kriteria ketuntasan siswa dengan nilai 75 dikategorikan Baik. Peneliti menggunakan data kriteria ketuntasan minimal dari guru penjaskes kelas VII 4 
SMP Negeri 5 Kuta Selatan.

\begin{tabular}{lcc}
\hline No & Kriteria atau nilai & Jumlah siswa \\
\hline & $\begin{array}{c}\text { Siswa yang mendapatkan nilai } \\
\text { diatas } \\
\text { KKM 75 }\end{array}$ & 18 siswa \\
\hline & $\begin{array}{c}\text { Siswa yang mendapatkan } \\
\text { nilai dibawah } \\
\text { KKM 75 }\end{array}$ & 12 siswa \\
\hline Jumlah & 30 siswa \\
\hline
\end{tabular}

Dari data penelitian kuesioner yang di rangkum sebanyak 30 siswa kelas VII 4 SMP Negeri 5 Kuta Selatan mengirimkan jawabannya melalui aplikasi media sosial whatsapp. Dari hasil nilai yang di dapat siswa kelas VII 4 lebih banyak diatas nilai KKM. Sebanyak 18 siswa mendapatkan nilai diatas KKM dan sebanyak 12 orang siswa mendapatkan nilai dibawah KKM.

Dari hasil kuesioner tersebut, siswa sudah mampu menjawab beberapa pertanyaan. Dari 30 siswa kelas VII 4 SMP Negeri 5 Kuta Selatan tidak ada siswa yang mampu menjawab semua pertanyaan dengan benar dan jelas. Dengan nilai maksimal kuesioner adalah 100, siswa hanya mampu pada nilai 80 .

Berdasarkan data diatas, maka dapat disimpulkan bahwa siswa kelas VII 4 SMP Negeri 5 Kuta Selatan sudah mampu menjawab dengan benar. Kemampuan memahami gerak dasar renang gaya dada dengan kualifikasi baik, terbukti dari hasil sebaran kuesioner rata - rata nilainya 75 -
80 .

\section{Pembahasan}

Berdasarkan hasil penelitian dapat diketahui bahwa kemampuan siswa dalam melakukan gerak dasar pada olahraga renang gaya dada berkategori baik dengan nilai persentase sebanyak $60 \%$. Artinya, ketika siswa memiliki kemampuan yang baik, tentu akan berdampak baik juga pada hasil pencapaian yang mereka peroleh. Pernyataan tersebut senada dengan (Pasaribu \& Daulay, 2018) yang mengatakan bahwa siswa dapat melakukan gerak dasar yang baik ketika memiliki kemampuan yang baik pula. Kemampuan siswa berasal dari dalam dirinya masingmasing yang memiliki kesanggupan dalam melakukan suatu aktivitas dalam hal ini ialah aktifitas renang (Maulana et al., 2018). Semakin baik kemampuan siswa, maka akan semakin baik/tepat pula cara siswa dalam melakukan teknik gerak dasar pada renang gaya dada.

Namun, terdapat $40 \%$ siswa yang mendapat nilai dibawah standar pencapaian pada saat penelitian yang menggunakan aplikasi whatsapp. Artinya terdapat beberapa faktor yang dapat menjadi pertimbangan diantaranya terdapat siswa yang masih berada di fase remaja awal. Sehingga perlu dilakukan bimbingan oleh 
guru kepada siswa agar ketika kemampuan yang dimiliki siswa menurun dapat meningkat kembali.

Dengan melakukan gerak dasar pada renang gaya dada yang sesuai, maka gerakan-gerakan pada olahraga renang selanjutnya akan dapat dilakukan dengan baik pula sesuai dengan teknik-teknik yang telah ditentukan. Untuk melakukan teknik yang sesuai diperlukan kemampuan yang baik pula agar teknik-teknik yang diajarkan dapat dilakukan dengan benar.

\section{Kesimpulan}

Berdasarkan penelitian yang telah dilakukan peneliti yang berfokus pada kemampuan gerak dasar renang gaya dada pada siswa kelas VII 4 SMP Negeri 5 Kuta Selatan sudah cukup baik. Dari hasil ketiga data obervasi, wawancara dan hasil kuesioner menghasilkan kesamaan data yang cukup maksimal (baik) dapat dilihat dari data tabel dan hasil wawancara diatas. Kemampuan gerak dasar renang gaya dada pada siswa kelas VII 4 SMP Negeri 5 Kuta Selatan dari data observasi ditemukan siswa dengan kategori sangat baik.

\section{Daftar pustaka}

Adriansyah, M. A., \& Rahmi, M. (2012). Faktor-Faktor Yang Mempengaruhi
Moralitas Remaja Awal. Psikostudia: Jurnal Psikologi, $\quad$ l(1), 1. https://doi.org/10.30872/psikostudia.v1 $\underline{\mathrm{i} 1.2122}$

Alvian, R., \& Nuruddin, A. A. (2019). Hubungan Kekuatan Otot Lengan Dan Kekuatan Otot Perut Terhadap Penguasaan Teknik Dasar Renang Gaya Dada. JPOS (Journal Power Of Sports), 2(2), 27-31. https://doi.org/http://doi.org/10.25273/i pos.v2i2.4970

Arhesa, S. (2020). Pengaruh Model Pembelajaran Directive Instruction Terhadap Keterampilan Gerak Dasar Renang Gaya Dada. Seminar Nasional Pendidikan, 864-869.

https://prosiding.unma.ac.id/index.php/ semnasfkip/article/view/397/380

Arifin, S. (2017). Peran Guru Pendidikan Jasmani Dalam Pembentukan Pendidikan Karakter Peserta Didik. Multilateral Jurnal Pendidikan Jasmani Dan Olahraga, 16(1). https://doi.org/10.20527/multilateral.v1 $\underline{6 i 1.3666}$

Dimyati, A. (2017). Pengembangan Model 
Permainan Atletik Anak Dalam

Pembelajaran Gerak Dasar Lari Bagi

Siswa Berkebutuhan Khusus

(Tunarungu) Di SLB Negeri Kabupaten

Karawang. Journal Sport Area, 2(2), 19-26.

https://doi.org/https://doi.org/10.25299/ sportarea.2017.vol2(2).1031

Erliza, Y. (2018). Peningkatan Pembelajaran Gerak Dasar Renang Dengan Pendekatan Bermain Siswa Kelas Iv Sdn 125 Kecamatan Pekanbaru Kota , Kota. Jurnal Educhild: Pendidikan Dan Sosial, 7(2), 107-112.

Illahi, Y. K. (2019). Kontribusi Koordinasi Mata Tangan , Keseimbangan , dan Kecepatan Terhadap Kemampuan Dribbling Bolabasket. JP\&O (Jurnal Pendidikan Dan Olahraga), Fakultas Ilmu Keolahragaan, Universitas Negeri Padang, 2(1), 142-148.

Kamadi, L. (2020). Kontribusi Kondisi Fisik Terhadap Kemampuan Servis Bawah Dalam Permainan Bolavoli Contribution of Physical Conditions to Lower Service Ability in Volleyball Games. Journal Coaching Education Sports, $\quad 1(2), \quad$ 151-160. https://doi.org/https://doi.org/10.31599/ jces.v1i2.369

Maulana, A., Azhari, A., \& Darmawan, A. (2018). Pengembangan Model Latihan Renang Berbasis Mobile Learning Untuk Mahasiswa Pendidikan Jasmani ,. Bravo's Jurnal, 6(4), 150-155. http://www.ejournal.stkipjb.ac.id/index. php/penjas/article/view/973

Mustafa, P. S., \& Dwiyogo, W. D. (2020). Kurikulum Pendidikan Jasmani, Olahraga, dan Kesehatan di Indonesia Abad 21. JARTIKA Jurnal Riset Teknologi Dan Inovasi Pendidikan, $3(2)$, $422-438$. https://doi.org/10.36765/jartika.v3i2.26 $\underline{8}$

Mustafa, P. S., Winarno, M. E., \& Supriyadi. (2019). Penilaian Pendidikan Jasmani, Olahraga, dan Kesehatan pada Sekolah Menengah Pertama Negeri Kota Malang. Jurnal Pendidikan: Teori, Penelitian, Dan Pengembangan, 4(10), 1364-1379. https://doi.org/http://dx.doi.org/10.1797 7/jptpp.v4i10.12845

Nugrahani, Farida, \& Hum, M. (2014). Metode Penelitian Kualitatif. Cakra 
Books.

Paramitha, S. T., \& Anggara, L. E. (2018).

Revitalisasi Pendidikan Jasmani untuk

Anak Usia Dini melalui Penerapan

Model Bermain Edukatif Berbasis

Alam. JURNAL PENDIDIKAN JASMANI DAN OLAHRAGA. https://doi.org/10.17509/jpjo.v3i1.1061 $\underline{2}$

Pasaribu, A. M. N., \& Daulay, D. E. (2018). Pengaruh Permainan Lari Estafet terhadap Kemampuan Gerak Dasar Motorik Kasar Siswa Kelas 3 SDN Karet II Kabupaten Tangerang. Jurnal Prestasi, 2(4), 9-14. https://doi.org/10.24114/jp.v2i4.11909

Pujianto, D., Sutisyana, A., Arwin, A., \& Nopiyanto, Y. E. (2020). Pengembangan Model Latihan Passing Sepakbola Berbasis Sasaran Teman. Journal Coaching Education Sports, 1(1), $1-12$. https://doi.org/10.31599/jces.v1i1.81

Purnomo Adi Pratama, Budiman Agung Pratama, Setyo Harmono, \& Septyaning Lusianti. (2020). Survei Implementasi Pembelajaran Pendidikan Jasmani Berdasarkan Kurikulum 2013
Di SMP Se Kecamatan Kertosono. Journal Coaching Education Sports, $1(2)$, 63-70. https://doi.org/10.31599/jces.v1i2.334

Rizkiyansyah, A., \& Mulyana, B. (2019). Pengaruh Media Papan Luncur dan Pull Buoy Pola Metode Drill terhadap Hasil Belajar Teknik Dasar Renang Gaya Bebas. Jurnal Kepelatihan Olahraga, 11(2), 112-123.

https://doi.org/10.17509/jko-

upi.v11i2.20311

Suherman, W. S. (2001). Pengembangan Kurikulum Pendidikan Jasmani. Yogyakarta: Fik Uny.

Tahapary, J. M., \& Syaranamual, J. (2020). Latihan Teknik Dasar Dapat Meningkatkan Hasil Renang Gaya Bebas. Jargaria Sprint: Journal Science of Sport and Health, 1(1), 3038.

Thomas, G. D. (2013). Renang: Tingkat Penula. PT. Raja Grafindo Persada.

Widodo, A. (2018). Makna Dan Peran Pendidikan Jasmani Dalam Pembentukan Insan. Jurnal Motion, 
9(1), 53-60.

https://www.researchgate.net/publicatio n/329442726_MAKNA_DAN_PERAN

_PENDIDIKAN_JASMANI_DALAM

_PEMBENTUKAN_INSAN_YANG_

MELEK_JASMANIAHTER-

LITERASI_JASMANIAHNYA

Wulandari, A. (2014). Karakteristik

Pertumbuhan Perkembangan Remaja

dan Implikasinya Terhadap Masalah

Kesehatan dan Keperawatannya. Jurnal

Keperawatan Anak, 2(1), 39-43.

https://jurnal.unimus.ac.id/index.php/J

$\underline{\text { KA/article/view/3954 }}$ 